
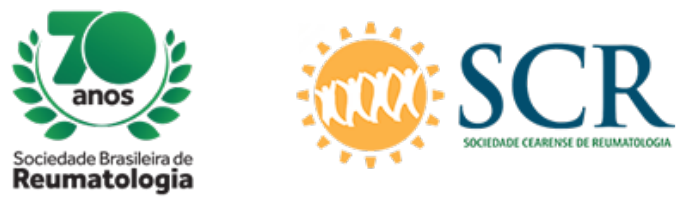

\title{
SYSTEMIC LUPUS ERYTHEMATOSUS ASSOCIATED WITH NEPHRITIC SYMPHROME IN AN INFANT PATIENT
}

Catarina Fernandes Pires (Universidade Federal do Piauí (UFPI), Teresina, PI, Brasil), Simone Soares Lima (UFPI, Teresina, PI, Brasil), Roberta Oriana Assunção Lopes Sousa (Hospital Infantil Lucídio Portella, Teresina, PI, Brasil), Dário Henrique Alvarenga Vale (UFPI, Teresina, PI, Brasil), Aparecida Maísa Carvalho Gomes (UFPI, Teresina, PI, Brasil), Ana Teresa Spíndola Madeira Campos (UFPI, Teresina, PI, Brasil), Antônio Silva Macêdo (UFPI, Teresina, PI, Brasil), Lucas Aguiar Alencar Oliveira (UFPI, Teresina, PI, Brasil), Pedro Vítor Lima Rêgo (UFPI, Teresina, PI, Brasil)

\section{BACKGROUND}

Systemic Lupus Erythematosus (SLE) is the prototypic autoimmune disease. It is characterized by multiple autoantibodies associated with multisystem illness. Pediatric lúpus has been estimated to account for $10 \%$ to $20 \%$ of all cases of SLS. The average age of onset is 12 years, with rare cases occurring at 5 years of age or younger. Diagnosis of Pediatric SLE occurs at a younger age in non-Caucasian populations.

\section{CASE REPORT}

1-year-and-1-month-old-girl, non caucasian, initially presented reduction in urinary volume (oliguria) associated with nausea and vomiting, which led the family to seek medical assistance. In the first moment, received treatment with gastrointestinal symptoms and water replacement in a primary care unit. During the treatment he presented hematuria and generalized edema, in addition to changes in pressure values. Due to this evolution, she was referred to a regional hospital, where was started a deeper investigation of the origin of the symptoms. At the time, the patient denied episodes of pharyngoamygdalitis or pyodermites, which spoke against acute diffuse glomerulonephritis (post-streptococcal). In addition, he presented urea of $98 \mathrm{mg} / \mathrm{dl}$ and creatinine of $0.99 \mathrm{mg} / \mathrm{dl}$. Due to this fact, investigation was initiated for other probable causes of nephritic syndrome, and the following tests were ordered: cardiolipin IgG (negative result), cardiolipin IgM (indeterminate result), anti-MS (negative result), anti-ssa (RO) (negative result), anti-ssb (LA) (negative result), anca's "c", "p" and atypical (non-reagents), FAN (reagent), C3 and C4 (within normal values), anti-DNAn (non-reagent) and cardiolipin IgA (non-reagent). Due to the results of the exams and the clinical picture, SLE was suspected as an etiology, being initiated the treatment with prednisone $2 \mathrm{mg} / \mathrm{kg}$, diuretics and hydric restriction. At the same hospital hospitalization, renal biopsy was performed for better elucidation and characterization of the condition. The result of this study was secondary membranous nephropathy, with minimal tubulointerstitial repercussion, presence of large amounts of IgG and low amounts of IgA, IgM and C3 in MBG (highly suggestive result of lupidic nephritis grade $\mathrm{V}$-MEMBRANE GLOMERULONEPHRITIS). Currently, the patient is undergoing treatment with pulse therapy (initially monthly and now quarterly) with 3 cycles of methylprednisolone and 1 of cyclophosphamide. Evolves with stabilization of the condition and good response to treatment, however, still follows with changes in renal function.

\section{CONCLUSION}

SLE is rare at 5 years of age or younger. especially with renal involvement which provides a higher degree of aggressiveness of the disease with catastrophic consequences to the patient. 